\title{
The entrepreneur's mode of entry: Business takeover or new venture start?
}

\author{
Simon C. Parker \\ University of Western Ontario
}

\author{
C. Mirjam van Praag \\ University of Amsterdam
}

\begin{abstract}
We extend the well-known occupational choice model of entrepreneurship by analyzing the mode of entry. Individuals can become entrepreneurs by taking over established businesses or starting up new ventures from scratch. We argue that the new venture creation mode is associated with higher levels of schooling whereas managerial experience, new venture start-up capital requirements and industry-level risk promote the takeover mode. A sample of data on entrepreneurs from the Netherlands provides broad support for these hypotheses, and also bear out a prediction that entrepreneurs whose parents run a family firm tend to invest the least in schooling. We go on to discuss the implications for researchers, entrepreneurs and public policy-makers.
\end{abstract}

Keywords: Business Start-up, Business takeover, Entrepreneur, Education, Human capital 


\section{Executive Summary}

It is common for researchers to analyze entrepreneurship in terms of new venture creation. Despite this emphasis, starting a new firm from scratch is not the only way individuals can become entrepreneurs. They can also take over an existing firm, including a family business if they come from a business-owning family. One can therefore distinguish the mode of entry from the entry decision itself. Yet we currently know very little about the factors which determine the mode of entry which individuals choose, despite its importance for entrepreneurship researchers and public policy-makers.

The present article aims to fill this lacuna. We develop a framework based on human capital theory and estimate it using a sample of data on Dutch entrepreneurs. The results show that important differences exist between the characteristics of entrepreneurs who opt for different modes of entry. We believe this carries several important implications for scholarship and practice. Most entrepreneurship researchers have not yet realized that the determinants of entrepreneurship entry might be distinct for different modes of entry. Some researchers define entrepreneurs as business owners and analyze the determinants of success or choice for this combination of self-starters and entrepreneurs who have taken over an existing firm. Other researchers define entrepreneurs as those who started a business and focus on the factors determining their performance. However, little attention is paid to the distinction we highlight and, usually, the results of both sorts of studies are treated as though these entry modes are comparable. Our study will show this is not always the case by showing that people with different human capital backgrounds are attracted towards different modes of entry.

Implications for practice arise because most governments in developed countries implement policies designed to encourage individuals to become entrepreneurs. For example, an ongoing policy debate is concerned with the dearth of possible successors to family businesses in contemporary developed economies. There are several reasons why economic value can be lost when small family-owned firms close without finding successors, which put jobs as well as wealth at risk. Hence we argue that the current focus of entrepreneurship policy on encouraging new market entry might need to be complemented with efforts to preserve economic value already embodied in established entrepreneurial ventures. Furthermore, our analysis suggests that policy-makers seeking to stimulate domestic entrepreneurship should recognize that policies designed to promote new starts might not necessarily be suitable for individuals who are contemplating entry by taking over an existing firm that seeks a successor. If targeted policies are to provide the correct incentives, it is necessary to take into account the mode of entry into entrepreneurship as well as the gross entry flow.

To provide the evidence needed to inform this debate, the present article asks the following questions: What are the determinants of an individual's decision to start up a business from scratch, or to take over instead an established firm looking for a successor? And, in the case of a takeover, when will individuals who come from a business-owning family take over a family 
business, and when will they acquire a firm from a third party? The lens we use to examine these questions is human capital theory, in particular the relationship between 'formal' human capital such as schooling, and 'informal' human capital such as transfers of business knowledge through exposure to family firms. Our conceptual discussion generates several hypotheses predicting how various dimensions of human capital, family background, capital requirements and market risk are likely to affect the mode of entry. These hypotheses are tested using a sample of data from the Netherlands, and identify several salient determinants of entry modes. The paper concludes with a discussion of implications of the findings, and suggestions about possible directions for future research. 


\section{Introduction}

An extensive literature now treats the decision to become an entrepreneur as an occupational choice. Recent research emphasizes the importance of several variables that may affect this decision, including borrowing constraints (Hurst and Lusardi, 2004; Parker and van Praag, 2006); human capital (Lazear, 2005; van Praag, 2005); geographical location (Acs and Armington, 2006); cognitive biases (Puri and Robinson, 2007; Lowe and Ziedonis, 2006; Hayward et al., 2006); genetic heritage (e.g., Nicolaou et al., 2008) and ethnicity (Fairlie, 2004). This literature focuses on entrepreneurship as a transition into independent business ownership, and usually frames entrepreneurship in terms of new venture creation. Despite this emphasis, starting a new firm from scratch is not the only way individuals can become entrepreneurs. They can also take over an existing firm, including a family business if they come from a business-owning family. One can therefore distinguish the mode of entry from the entry decision itself.

There are at least two reasons why policy-makers may be concerned with the mode of entry. First, the population is aging, especially in Europe, thereby increasing the potential for business transfers. According to the European Commission, 'one third of EU entrepreneurs, mainly those running family enterprises, will withdraw within the next ten years. According to estimates this could affect up to 690,000 small and medium sized enterprises and 2.8 million jobs every year' (Commission of the European Communities, 2006, p.3). The importance of business takeovers is also underlined by national data. For example, based on the age distribution of business owners, 20,000 firms per year are expected to seek takeover candidates in the next five years in the Netherlands. In comparison, 70,000 firms are started every year in the Netherlands (data source: The Dutch Ministry of Economic Affairs). At the same time, the proportion of firms being taken over by family members is decreasing sharply in several countries. One reason is that parents are having fewer children, which decreases the probability of finding suitable takeover candidates among one's own offspring. Another is that wider access to education has broadened the career options of younger people, many of whom now have more attractive alternatives to continuing a family firm. Thus research conducted by ING bank reveals that in the period 1994-1999, 35\% of Dutch firm owners sold their firm to a family member, whereas the corresponding percentage in 2003 was only $22 \%$. In Canada, four out of ten small business owners are expected to retire within the next five years, and seven out of ten will retire within the next decade, according to evidence given by the Canadian Federation of Independent Business (CFIB) to the Canadian Standing Senate Committee on Banking, Trade and Commerce in June 2006. The CFIB estimates that almost $58 \%$ of heads of SMEs anticipate retiring in two years without having identified a successor, with two-thirds failing to start any planning for their future succession. Likewise, the UK Small Business Service identified one third of British SME owners as vulnerable to age-related transfer failure (Commission of the European Communities, 2006). 
There are several reasons why economic value can be lost when small family-owned firms close and seek external successors. First, unlike large firms, many small family-firms lack tangible assets which can be easily redeployed to other uses. Instead, much of the value is embodied in the networks and idiosyncratic expertise of the small firm owner-manager him or herself. A second, related, point is that unlike large incorporated firms, where detailed accounting and operational information is usually available in a highly systemised form, small family firms are prone to less rigorous reporting requirements and tend to be more informationally opaque to outside investors. Outside investors therefore face a classic asymmetric information problem, which can be expected to make them more reluctant to invest in takeovers of small firms when they close. Third, it can be costly and time-consuming for entrepreneurs to find suitable successors from outside the family, implying that aggregate transaction and operation costs are likely to increase as the number of family firms taken over by 'outsiders' rises. For all these reasons, 'a small business owner will tend to sell at a discount to competitors, ... with the associated risk of business closure' - putting as many as two million jobs at risk in Canada, according to CFIB.

Under-investment in taking over small firms might be privately rational but has potentially adverse social welfare implications. This is potentially a serious problem because a substantial amount of economic value is bound up in private (non-publicly traded) firms. Europe's 18 million SMEs employ $66 \%$ of the workforce and generate $55 \%$ of total turnover (Eurostat, 2000). These figures illustrate an important, but sometimes overlooked, consideration in the entrepreneurship debate: the importance of preserving the economic value of existing entrepreneurial firms as well as creating value via new starts. ${ }^{1}$ This provides an important motivation for analyzing the choice of entrepreneurial entry between takeover and brand new starts.

The second reason why the mode of entry is of policy interest relates to the growing trend in public policy towards promoting entrepreneurship. The European Commission Green Paper on Entrepreneurship (2003) is only one of a recent raft of policy initiatives of this kind. As noted there, 'The challenge for the European Union is to identify the key factors for building a climate in which entrepreneurial initiative and business activities can thrive. Policy measures should seek to boost the Union's levels of entrepreneurship, adopting the most appropriate approach for producing more entrepreneurs and for getting more firms to grow' (European Commission, 2003, p. 9). Yet it does not necessarily follow that a set of policies designed to promote new starts will also be suitable for individuals who are contemplating entry by taking over an existing firm that seeks a successor. If targeted policies are to provide the correct incentives, it is necessary to take into account the mode of entry into entrepreneurship as well

\footnotetext{
${ }^{1}$ The European Commission again: 'In general, family businesses with their long-term orientation provide an important element of stability to our economies and are the source of a wealth of genuine corporate social responsibility-practices ... More successful business transfers will have immediate beneficial effects for Europe's economy. Existing companies conserve on average five jobs whereas a start-up generates on average two jobs' (Commission of the European Communities, 2006, p. 3-4).
} 
as the gross entry flow. However, to our knowledge, the entry mode of entrepreneurs has been little studied to date. In particular, we still know little about which types of individual match with which types of firm (i.e., takeover or start-up) as the owner-manager.

This paper analyzes the entrepreneurial entry mode decision, in an effort to shed light on the following questions: What are the determinants of an individual's decision to start up a business from scratch, or to take over instead an established firm looking for a successor? And, in the case of a takeover, when will individuals take over a family business, and when will they acquire a firm from a third party, given that a family business is available in the family? We develop a framework based on human capital theory and test the propositions resulting from this framework using a sample of Dutch entrepreneurs. The central argument advanced in this paper is based on a distinction between formal human capital and informal human capital. Whereas formal human capital is a set of skills and capabilities conveyed by formal education and work experience, we define informal human capital as comprising skills and knowledge transmitted from business-owning parents to their offspring. Our conceptual discussion generates several hypotheses predicting how various dimensions of human capital affect the mode of entry. These hypotheses guide the empirical analysis which helps identify the salient determinants of entry mode. We believe our findings provide valuable evidence on a little researched issue, and carry interesting implications for researchers, entrepreneurs and public policy-makers.

Reflecting an emphasis in the empirical literature on the family succession problem from the departing founder's perspective rather than the potential successor's, the existing literature on entrepreneurs' modes of entry is rather limited. One of the few papers to explore this issue is the descriptive study by Cooper and Dunkelberg (1986). Those authors analyzed entry via new starts, inheriting a business, and taking over an external business - as well as promotions within family firms. Using survey responses from 1,756 members of the US National Federation of Independent Business sampled in 1979, Cooper and Dunkelberg described each entry mode in terms of entrepreneurs' background characteristics, motivations and attitudes and previous careers. However, Cooper and Dunkelberg did not conduct a multivariate statistical analysis of the determinants of entry mode, which is the focus of enquiry here. ${ }^{2}$

There is also a limited amount of conceptual work on business transfers and takeovers. Holmes and Schmitz (1990) investigate the circumstances under which entrepreneurs decide whether to continue operating a venture or to transfer it to a possibly less able entrepreneur, thereby releasing time and resources to explore new opportunities. Holmes and Schmitz deal more with entrepreneurs' decisions about how to dispose of existing ventures than with their decisions about how to enter. Others have identified borrowing constraints as barriers to takeovers (Caselli and Gennaioli, 2005), though this too does not consider alternative entry modes. Nor does the literature analyzing whether family firm founders decide to appoint

\footnotetext{
${ }^{2}$ Another study, by Chaganti and Schneer (1994), explored performance outcomes of firms as a function of different modes of entry. This topic is not explored in the present paper.
} 
either a family or an external CEO (Burkart et al, 2003; Bennedsen et al, 2006).

The remainder of the paper is structured as follows. Section 3 presents a conceptual discussion of the entry-mode decision of entrepreneurs. Section 4 describes our sample data, and outlines the modes of entrepreneurial entry observed in the sample. Section 5 presents the empirical results, and Section 6 concludes with a discussion of implications for policy-makers, limitations of this study and suggestions about possible directions for future research.

\section{Conceptual discussion}

In the following, we focus on two types of entrepreneur and three types of firm. The two entrepreneur types are $f$ and $g$ : $f$ types are born into families owning a family business, and $g$ types are born into families without a family business. The three firm types are family firms looking for successors who belong to the family, F; ventures seeking a successor from outside the family, T; and new start-ups, N. ${ }^{3}$ The last two types of firms can be operated by anyone, but by definition only $f$ type entrepreneurs can operate the first type. Hence after analyzing the attractiveness of $\mathrm{F}$ matches for $f$ types, we will focus on choices between $\mathrm{N}$ and $\mathrm{T}$ for both $g$ types and those $f$ types who do not enter via F. We will only investigate the entry strategies of individuals who have chosen to be entrepreneurs; the decision to enter entrepreneurship in the first place will not be analyzed here. ${ }^{4}$

We start by distinguishing between 'formal' and 'informal' human capital. Following Becker (1964), human capital is defined as the stock of skills, knowledge, experience and capabilities which are useful in a multitude of productive uses. Formal human capital is transferred by formal institutions, such as schools providing education and firms providing work experience. Informal human capital on the other hand is the set of skills and knowledge transferred through informal institutions, such as a parent's business. Evidently, at least as we have defined it, $f$ types have access to more sources of informal human capital than $g$ types who do not have access to informal human capital obtained through being born in a business owning family (Fairlie and Robb, 2007).

A long tradition of research links formal human capital with the decision to participate in entrepreneurship (see a meta analysis by Van Der Sluis et al., 2008). For example, it has been argued that education can improve entrepreneurial judgement by providing people with analytical abilities, information about business opportunities, and an understanding of markets and the entrepreneurial process (Casson, 1995; Ucbasaran et al. 2009). Formal education is

\footnotetext{
${ }^{3}$ We are aware that this does not exhaust the set of possible entry modes. Franchising and management buyouts are two other possibilities. We lack the data to explore the determinants of these choices in the present paper.

${ }^{4}$ This choice has been extensively treated elsewhere: see e.g., Parker (2009) for a survey. Ignoring the decision to enter entrepreneurship makes no difference to the central results while avoiding the need to identify an occupational sample selection structure in the empirical work. It is also consistent with our data sample which relates only to entrepreneurs.
} 
also associated with general search skills, foresight, imagination, and computational skills, as well as with specific skills and knowledge needed to run businesses in particular sectors. A considerable body of evidence supports the notion that formal education enhances the business performance of entrepreneurs (e.g., Parker and Van Praag, 2006; and Van Der Sluis et al., 2008 for the results of a meta-analysis). Work experience is also believed to promote entrepreneurship, by enabling individuals to understand business opportunities and how enterprises work in practice. Experience embodies knowhow needed to exploit opportunities, such as selling, negotiating, leading, planning, decision-making, problem solving, organising and communicating (Shane, 2003, p. 75). Learning also generates information which reduces uncertainty about the value of exploiting entrepreneurial opportunities (Jovanovic, 1982; Parker, 2007; Ucbasaran et al., 2009). Thus, formal human capital in general is associated with successful, value-creating entrepreneurship.

Informal human capital conveyed through familiarity with a parent's business is likely to comprise knowledge about what is involved in owning and managing a business, and may transfer learning from favorable role models within the family (Cooper and Dunkelberg, 1986). Informal human capital might also provide access to valuable business networks and resource providers. Consistent with these arguments, Fairlie and Robb (2007) uncovered a significant positive linkage between business owners' experience obtained from previously working in a family member's business and their own subsequent success. In contrast, Fairlie and Robb observed that merely having a family member who owned a business had no significant effect. These findings suggest that experience of working in a parent's venture involves the transfer of performance-enhancing informal human capital. A recent paper by Robinson (2009) shows that the probabilities of adult entrepreneurship and subsequent wealth acquisition are significantly higher for individuals who obtained entrepreneurial experience as adolescents, especially among those born into business owning families.

One might wonder about the relative productivity of formal and informal human capital, in entrepreneurship in general and the three entry modes in particular. Human capital theory suggests that formal human capital is the most versatile, since it generates high returns in paid-employment as well as entrepreneurship (Card, 2001; Oreopoulos, 2006; Parker and van Praag, 2006; Van Praag et al., 2009). In contrast, there is no clear cut evidence of the value of prior experience of business ownership outside of business ownership, where its effects can even be negative (Bruce and Schuetze, 2004; Landier, 2004; Hyytinen and Rouvinen, 2008).

The value of informal human capital obtained in family businesses for wage employment, has, as far as we know, not been put to a test. However, it is likely to be more valuable in entrepreneurship where it is more compatible. ${ }^{5}$ Furthermore, informal human capital is likely to be most valuable when it is deployed within the same family business that conferred the

\footnotetext{
${ }^{5}$ Informal human capital also has no signalling value in the labor market of paid employees because experience obtained in a family business is difficult to communicate credibly as is required for valuable signals in labor markets without complete information (Spence, 1973; Riley, 2002).
} 
informal human capital in the first place, since this leverages specific as well as general elements of the informal human capital. Because people for whom the probability of becoming an entrepreneur is high are likely to seek human capital which is most useful in entrepreneurship, we would expect them to acquire relatively cheap-to-obtain informal human capital which is readily accessible in the family business, if available. People for whom the probability of entrepreneurship is smaller on the other hand would be expected to seek out more formal types of human capital. This reasoning is borne out by evidence showing that the likelihood of becoming an entrepreneur (irrespective of the mode of entry) is about three times higher for $f$ types than $g$ types (Robinson, 2009; Colombier and Masclet, 2008; Parker, 2009).

To summarize, we would therefore expect $f$ types, who may have an option to inherit and run the $\mathrm{F}$ type business, and who are in general more likely to become entrepreneurs, to invest more in informal human capital and less in formal human capital than $g$ types. For example, they can spend fewer years in school and college, spending their time instead working in the family business. This will be a more attractive strategy the more easily accessible is informal human capital, and the more productive it is in entrepreneurship. Thus anticipating the prospect of future market entry in general and the possibility of entry via $\mathrm{F}$ in particular, $f$ types are predicted to obtain less formal education on average than $g$ types. Indeed, some French evidence is consistent with this prediction, indicating that people without self-employed parents obtain more formal human capital than those with self-employed parents (Colombier and Masclet, 2008). This gives rise to our first proposition:

Proposition 1. Entrepreneurs born into business-owning families ( $f$ types) obtain less formal education than those born into non-business-owning families (g types) because the former specialize in informal human capital.

It seems likely moreover that formal human capital will be especially useful for starting brand new firms relative to taking over firms (inside or outside of the family). As noted above, formal education improves a person's ability to search and process large amounts of information. For example, formal education has been shown to be associated with more intense and effective job search (Boheim and Taylor, 2001). And higher levels of education seem to be associated with a greater ability to identify potential business opportunities (Ucbasaran et al., 2009).

The abundance of possibilities in $\mathrm{N}$ compared with $\mathrm{T}$ is therefore likely to make formal human capital more productive in $\mathrm{N}$ than in $\mathrm{T}$. This expected effect is attributable to its greater productivity in searching for new opportunities to exploit.

There are other reasons as well why higher levels of education might favor $\mathrm{N}$ over $\mathrm{T}$. One might be the greater degree of difficulty in establishing a new start-up in which routines and organizational structures have to be created from scratch. Here again versatile formal human capital can confer an advantage. Another reason might be that formal human capital can serve as a hedge, making it possible for risk-averse entrepreneurs to undertake projects occupying 
a higher point on the risk-return trade-off (Polkovnichenko, 2003; Cocco et al, 2005; and Gomes and Michaelides, 2005). These risky projects are especially likely to be N-type ones (Cooper and Dunkelberg, 1986; and see the evidence below). This predisposes highly educated individuals of both types to try risky $\mathrm{N}$, since if they fail they still have other opportunities, reflecting the general usefulness of formal human capital. For all these reasons, we have the next proposition:

Proposition 2. More educated entrepreneurs are more likely to enter via $N$ than $T$.

By taking over the family firm, $f$ types can economize on the costs of searching for new business opportunities $\mathrm{N}$ or suitable takeover targets $\mathrm{T}$. And, having less formal education (by Proposition 1), $f$ types have lower capabilities anyway for identifying new venture opportunities of the $\mathrm{T}$ and $\mathrm{N}$ types. Hence we would expect many $f$ types to choose $\mathrm{F}$ should it be available. Of course, not every $f$ type is temperamentally suited to taking over their family firm $\mathrm{F}$ - and even those who are may not be chosen by their parents to do so. In which case, like $g$ types these non-F $f$ types have to choose between the $\mathrm{N}$ and $\mathrm{T}$ entry modes.

The first two propositions together imply that these non- $\mathrm{F} f$ types who have to choose between $\mathrm{N}$ and $\mathrm{T}$, and, who have, ceteris paribus, lower levels of education and thus of formal human capital than $g$ types, are relatively more inclined to become entrepreneurs through the entry mode $\mathrm{T}$ than $\mathrm{N}$.

Moreover, a key feature of informal human capital - namely, that it is obtained in, and is directly applicable to, established ventures - helps predict what choices $f$ types will make relative to $g$ types. In general, one would expect that informal human capital will be more transferable to $\mathrm{T}$ ventures (which are already established) than to $\mathrm{N}$ firms (which are not). The next proposition then follows immediately:

Proposition 3. $f$ types are more likely than $g$ types to enter via $T$ than $N$, even after controlling for the entrepreneur's education level.

Another important dimension of formal human capital, stressed by Cooper and Dunkelberg (1986), is managerial experience. As those authors point out, greater experience managing others is likely to be most productive in firms which use and reward such experience. Because $\mathrm{T}$ ventures typically employ others whereas $\mathrm{N}$ ventures do not, at least in the beginning, managerial experience is therefore more likely to be most productive in ventures of the $\mathrm{T}$ rather than the $\mathrm{N}$ type. In contrast, other types of experience, such as general labor market experience, industry experience, and previous business experience might be more critical in $\mathrm{N}$ ventures than in $\mathrm{T}$ or $\mathrm{F}$ ventures where other personnel are already engaged and can substitute for any shortfalls in these types of an entrepreneur's generic experience. In other words, and in line with outcomes from a recent area of research initiated by Lazear (2005), entrepreneurs who start up new ventures need to be Jacks of all Trades (Astebro and Thompson, 2007; Douhan, 2009; Hartog et al., 2009; Silva, 2007; Wagner, 2003). As we have explained, this requirement 
will be less stringent for business takeovers. Hence individuals with abundant amounts of generic experience can exploit valuable new opportunities in $\mathrm{N}$ which other less experienced people will be unable to. We summarize these arguments in the next two propositions:

Proposition 4. All else equal, entrepreneurs with greater managerial experience are more likely to enter via $T$ than $N$, compared with otherwise identical entrepreneurs with less managerial experience.

Proposition 5. All else equal, entrepreneurs with greater labor market experience, industry experience, and previous business experience are more likely to enter via $N$ than $T$, compared with otherwise identical entrepreneurs with less of these types of experience.

A further consideration is that established firms are less risky than brand new firms (Cooper and Dunkelberg, 1986). Indeed, recent evidence shows that on average brand new ventures have more variable growth and profit rates and lower survival rates than established firms do (Astebro and Bernhardt, 2003; van Praag, 2003; Parker, 2009; and see below for evidence based on our data sample). Part of the risk of $\mathrm{N}$ firms can be shared with lenders; but problems of asymmetric information are more acute in $\mathrm{N}$ firms compared with established firms $\mathrm{T}$ or $\mathrm{F}$, owing to the lack of a track record. As a result, access to finance and hence entry into $\mathrm{N}$ is more difficult the greater are capital requirements in N (Parker and van Praag, 2006). This gives rise to our final proposition:

Proposition 6. Entrepreneurs facing higher start-up capital requirements and risk are more likely to enter via $T$ than $N$.

\section{Data}

The dataset used to test the hypotheses derived above is a random cross-section sample of Dutch entrepreneurs. Entrepreneurs are defined as individuals who started their own business from scratch or who took over an existing firm. ${ }^{6}$ The dataset contains a range of economic and demographic variables including ones related to family background, entry mode, and human and financial capital. The same dataset is used in Parker and Van Praag (2006).

In fall 1994, a questionnaire was sent to 1,069 entrepreneurs who had already indicated their willingness to participate in the research. Of these, 709 responded. Owing to nonresponse rates on some questions, most of the regression analyses below are based on between 600 and 640 observations. ${ }^{7}$

\footnotetext{
${ }^{6}$ The sample was generated as part of a private-public joint venture undertaken by the University of Amsterdam, The Erasmus University of Rotterdam, and the GfK market research company. The research for which the sample was gathered was commissioned by RABO, a large Dutch co-operative bank, and the General Advisory Council of the Dutch Government.

${ }^{7}$ When financial capital variables are included this number is reduced to 566 . This is partly attributable to non-response for these items, and partly to the fact that we dropped observations whose (absolute) values exceeded the mean by more than ten times the standard deviation - in order to limit the influence of outliers on the estimates.
} 
As documented in Brouwer et al (1996), the sample is broadly representative of the Dutch population of entrepreneurs in terms of industry, company size, legal form, and age of companies and entrepreneurs. The sample contains a slightly higher proportion of highly educated respondents than is found in the general Dutch population, reflecting the fact that one of the commissioners of the research project (the General Advisory Council of the Dutch Government) was particularly interested in the business outcomes of this group.

The remainder of this section outlines the variables used in the empirical analysis.

\subsection{Variables}

\section{A Entry mode}

In terms of the survey questionnaire, we coded entrepreneurs' entry strategies based on responses to the following question: "Did you start up the firm yourself or did you take over the firm?" There were three possible categorized answers: (i) "I have taken over a family firm", F; (ii) "I have taken over a firm from a non-family member", T; and (iii) "I have started the firm myself from scratch", N. Table 1 shows that of the 705 entrepreneurs who answered this question, 9.5\% took over a family firm, 7.4\% took over another firm and 83.1\% started a firm from scratch. Hence in total $16.9 \%$ of the firms were started through a takeover of some kind. ${ }^{8}$

\section{B Entrepreneurial family background}

We can take as the set of $f$ types all individuals who had at least one parent mainly engaged in entrepreneurship during the respondent's youth. ${ }^{9}$ All other individuals were coded as $g$ types. On this basis, Table 1 shows that $45.7 \%$ of the entrepreneurs in our sample come from entrepreneurial families. This compares with a figure of $51 \%$ identified in the US Characteristics of Business Owners (CBO) Survey by Fairlie and Robb (2007); and with Lentz and Laband's (1990) figure of $52 \%$ based on US National Federation of Independent Businesses (NFIB) data. Also, in our sample $9.5 \%$ of businesses are inherited or taken over from the family. Lentz and Laband (1990) reported that $14.2 \%$ of the businesses in their NFIB sample were inherited or acquired from family members, while Fairlie and Robb (2007) reported a lower figure of at most $8.2 \%$ (=1.6\% inherited plus an upper bound of $6.6 \%$ gifted or transferred) from the CBO database. It is also noteworthy that $f$ types are significantly less likely to start a new firm from scratch $(70.3 \%)$ than $g$ types are (94.0\%). Although $f$ types are slightly more likely to

\footnotetext{
${ }^{8}$ These figures compare with $15 \%$ in F, $28 \%$ in $\mathrm{T}$ and $49 \%$ in $\mathrm{N}$ in Cooper and Dunkelberg's (1986) US sample, and with $18 \%$ in F, $16 \%$ in $\mathrm{T}$ and $66 \%$ in $\mathrm{N}$ in Chaganti and Schneer's (1994) US sample.

${ }^{9}$ The precise question in the survey was: "Which professional status applied to your parents (or those who fulfilled this role for you) during the longest period in your youth?" Eight possible categories were given, including ones for self-employed (non-incorporated) and fully incorporated businesses — both of which are taken to be entrepreneurs. We acknowledge that we might define erroneously as $g$ types instead of $f$ types respondents whose parents did not own a business while a member of the extended family (e.g., an uncle) did. In that case our empirical definition of $f$ types could be too narrow. In fact, the dataset contained no respondents claiming to have taken over a family firm neither of whose parents was classified an entrepreneur.
} 
Table 1: Descriptive Statistics

\begin{tabular}{|c|c|c|c|c|c|}
\hline \multirow[b]{2}{*}{ Entry mode } & \multirow[t]{2}{*}{$N$} & \multirow[t]{2}{*}{ Mean } & \multicolumn{2}{|c|}{ Family Background } & \multirow[t]{2}{*}{ t-value } \\
\hline & & & $f$ types & $g$ types & \\
\hline New start, $\mathrm{N}$ & 705 & $83.1 \%$ & $70.3 \%$ & $94.0 \%$ & 8.12 \\
\hline Takeover & 705 & $16.9 \%$ & $29.7 \%$ & $6.0 \%$ & 8.12 \\
\hline of family firm, $\mathrm{F}$ & 705 & $9.5 \%$ & $20.7 \%$ & $0.0 \%$ & 9.38 \\
\hline of non-family firm, $\mathrm{T}$ & 705 & $7.4 \%$ & $9.0 \%$ & $6.0 \%$ & 1.52 \\
\hline \multicolumn{6}{|l|}{ Family background } \\
\hline$f$ type & 709 & $45.7 \%$ & $100 \%$ & $0 \%$ & \\
\hline$g$ type & 709 & $54.3 \%$ & $0 \%$ & $100 \%$ & \\
\hline \multicolumn{6}{|l|}{ Human capital } \\
\hline Formal education (years) & 703 & 14.7 & 14.1 & 15.2 & 4.63 \\
\hline General track (dummy) & 703 & 0.53 & 0.52 & 0.55 & 0.79 \\
\hline Prof. Track (dummy) & 703 & 0.47 & 0.49 & 0.46 & 0.79 \\
\hline Labor experience (years) & 686 & 10.6 & 10.2 & 10.9 & 0.98 \\
\hline Industry experience (years) & 686 & 4.60 & 4.30 & 4.90 & 1.18 \\
\hline Previous business exp. (dummy) & 686 & 0.14 & 0.17 & 0.12 & 2.02 \\
\hline People management exp. (dummy) & 686 & 0.41 & 0.41 & 0.41 & 0.07 \\
\hline Age at entry (years) & 686 & 33.90 & 33.20 & 34.40 & 1.75 \\
\hline \multicolumn{6}{|l|}{ Other variables } \\
\hline Female (dummy) & 709 & 0.18 & 0.18 & 0.17 & 0.28 \\
\hline Siblings & 685 & 3.24 & 3.85 & 2.75 & 5.81 \\
\hline Number of elder siblings as $\%$ of total & 685 & 0.54 & 0.74 & 0.39 & 9.30 \\
\hline Father's education (years) & 674 & 11.41 & 10.88 & 11.87 & 3.50 \\
\hline Entry year (19..) & 698 & 87.15 & 83.95 & 89.79 & 8.04 \\
\hline Initial capital invested ${ }^{a}$ & 515 & 81.18 & 99.85 & 66.48 & 1.89 \\
\hline Initial capital required ${ }^{a}$ & 515 & 101.57 & 136.22 & 74.26 & 2.93 \\
\hline Extent of initial capital constraint & 515 & 17.81 & 19.12 & 16.79 & 0.89 \\
\hline Initially capital constrained (dummy) & 515 & 0.33 & 0.35 & 0.31 & 1.04 \\
\hline \multicolumn{6}{|l|}{ Industries } \\
\hline Capital intensve & 709 & 0.121 & 0.130 & 0.119 & 0.62 \\
\hline Agriculture & 709 & 0.059 & 0.111 & 0.016 & 5.37 \\
\hline Production/building & 709 & 0.107 & 0.114 & 0.101 & 0.55 \\
\hline Trade & 709 & 0.096 & 0.108 & 0.086 & 1.00 \\
\hline Retail-food & 709 & 0.058 & 0.083 & 0.036 & 2.67 \\
\hline Retail-non food & 709 & 0.049 & 0.056 & 0.044 & 0.70 \\
\hline Repair/transport & 709 & 0.035 & 0.040 & 0.031 & 0.64 \\
\hline Financial services/housing & 709 & 0.025 & 0.025 & 0.026 & 0.11 \\
\hline Professional services & 709 & 0.398 & 0.296 & 0.483 & 5.06 \\
\hline
\end{tabular}


Notes

The first column shows the available sample size, $N$, for each variable. The second column provides the mean for the available sample; the third and fourth columns distinguish entrepreneurs who come from families owning a business ( $f$ types) and those who do not ( $g$ types); and the fifth column shows the t-statistic resulting from testing whether the differences between $f$ and $g$ types are statistically different. For dummy and proportional variables, an equality of proportions test is used, resulting in a $Z$ statistic. Observations with (required) entry capital levels exceeding the mean levels by more than ten times the standard deviation were dropped from the analysis.

${ }^{a}$ In thousands of 1994 Dutch guilders.

take over a non-family firm (9.0\%) than $g$ types are $(6.0 \%)$, this difference is not statistically significant in a simple univariate comparison.

\section{Human capital variables}

Education is measured in terms of the number of years of schooling rather than the highest schooling level attained. On average, the entrepreneurs in the sample have 14.7 years of formal education. In accordance with Proposition $1, f$ types have significantly less education on average than $g$ types do (14.1 versus 15.2 years). Also, a higher proportion of $f$ types (17.3\%) had business experience prior to operating the current venture than $g$ types (11.9\%); this difference is also statistically significant. Other characteristics, including whether the entrepreneur's schooling was general or followed a professional track; years of previous experience in the labor market, industry, or management; and their age when they began operating the current venture, are similar for the two entrepreneurial groups. These are only univariate comparisons, however: testing based on multivariate analysis will be performed in the next section.

\section{Other variables}

Proposition 6 states that entrepreneurs facing higher start-up capital requirements and risk are more likely to take over an existing firm than to start up a new one. When it comes to comparing both average start-up capital requirements and risk between firm types, as is required to test Proposition 6, individual-level data face an important limitation. Start-up capital requirements and risk can only be measured at the individual level for entrepreneurs who started up a business from scratch. However, we need to measure these variables for all entrepreneurs in the sample. For this reason we define both variables at the industry level; nine industries are distinguished for this purpose. Capital entry requirements at the industry level are measured as the mean value of the capital that entrepreneurs who start up from scratch initially invested in their business operating in the industry. This value is then attributed to all entrepreneurs in the sample who operate in the industry, i.e., including those 
who take over existing businesses. Likewise, the business risk of a new venture is defined as the within-industry standard deviation of profits (incomes) that are generated in the industry, based on new start-ups only. Again, this value is attributed to all entrepreneurs in the sample who operate in the same industry, whether through takeover or through a new start-up. ${ }^{10}$

Other variables used in the empirical work include gender, the number of siblings and the number of years of schooling of the entrepreneur's father. $18 \%$ of the entrepreneurs in the sample is female. This percentage is broadly consistent with other European studies (Parker, 2009, Chap. 6) and is similar for $f$ types and $g$ types. Previous researchers have found the number of siblings and father's education to be strongly correlated with determinants of entrepreneurs' schooling levels (see Parker and Van Praag, 2006). Moreover, the number of siblings as well as the rank of the respondent in the group of siblings is likely to affect the probability that an $f$ type has a family firm available: the more (older) siblings a respondent has, the lower the respondent's likelihood of taking over the family business, all else equal. The modal number of siblings in the sample is $3 . f$ types have significantly more siblings than $g$ types. The average age rank of the entrepreneurs within the group of sibling is 0.54 ; it is significantly higher for $f$ types than for $g$ types, partly because the rank is 0 if an individual has no siblings; and more $g$ types lack siblings than $f$ types do. The average number of years of schooling of the entrepreneur's father is 11.4; the number is significantly lower for $f$ types than for $g$ types.

To control for time trends, we also include the year of entry into our analyses. The year in which the venture was started or taken over is significantly earlier for $f$ types than for $g$ types. We control for industry effects too: industry dummies are used in all analyses except those which use industry-wide measures of business risk and entry requirements (see the earlier discussion). The bottom part of Table 1 shows the descriptive statistics of these variables. Agriculture is a significantly more important sector of activity among $f$ types than among $g$ types. The same holds for the retail (food) sector and the opposite is true for the professional services sector.

\section{Empirical results}

The results are presented in two stages. The first deals with the effects of family background on choices of formal education and entry into F. The second identifies the factors which predispose entrepreneurs to choose between the $\mathrm{N}$ and $\mathrm{T}$ modes of entry. The following subsections present evidence for each of these questions in turn, and we close with several robustness checks.

\footnotetext{
${ }^{10}$ For brevity, the values of these variables for each industry are not shown in Table 1.
} 


\subsection{The effects of family background on schooling and F entry}

Proposition 1 asserted that $f$ types optimally choose lower levels of formal education than $g$ types. The logic was that $f$ types can substitute informal for formal human capital. Table 1 has already shown that $f$ types have significantly fewer years of schooling than $g$ types, 14.1 years compared with 15.2 years. However, these are simple averages, which might be explained by different characteristics of the $f$ and $g$ sub-samples. Previous researchers have identified several variables that affect schooling choices, including age (negatively: capturing cohort effects), female gender (negatively: possibly reflecting different historic expectations about labor force participation rates), parental education (positively: reflecting both nature and nurture), and the number and rank of siblings (negatively: suggesting a trade-off between the quality and quantity of children, and greater investment by parents in older children). ${ }^{11}$ For example, according to Table $1, f$ types are significantly older than $g$ types, as they have an earlier entry year and a similar age at entry compared with $g$ types. Also, the fathers of $f$ types have lower levels of education, and $f$ types have more siblings, on average, than $g$ types do. These differences alone might explain the difference in mean number of years of schooling between the entrepreneur types. Offsetting this, $f$ types rank higher in the sibling rank than $g$ types do on average, which might partly compensate for the differences just described. We run OLS regressions to control for all of these variables together. We continue to include entrepreneurs in all industry sectors (including agriculture) to avoid possible sample selection biases entailed by studying the schooling decisions of only those who subsequently chose to enter particular sectors.

Table 2 reports the empirical results. The dependent variable is the number of years of education. ${ }^{12}$ The results are shown for $f$ and $g$ types together and separately, to highlight the potentially different mechanisms underlying the education investment decision of the different entrepreneurial types. For all three cases, two sets of results are presented. The first set excludes the variables that differ largely across $f$ types and $g$ types (i.e. father's education, the number of siblings and the individual's rank in the row of siblings), whereas the second set includes these variables.

The first entries in Table 2 show that $f$ types do indeed have significantly lower levels of formal education than $g$ types. This difference is large compared with other effects even after controlling for other covariates of schooling. Age, father's education, and the number and rank of siblings all significantly affect entrepreneurs' years of education, and carry the expected signs. That is, younger people with highly educated fathers and fewer siblings are significantly more likely to have more years of schooling. Together these variables account for a large part of the cross-sectional variation in the number of years of schooling, as demonstrated by the $R^{2}$ value of $33 \%$.

\footnotetext{
${ }^{11}$ See, e.g., Black et al (2005) and Parker and Van Praag (2006).

${ }^{12} \mathrm{~A} \log$-transformation of this variable generated similar results.
} 
Table 2: Determinants of years of schooling

\begin{tabular}{l|l|l|l|l|l|l}
\hline Variable & \multicolumn{2}{|c|}{ All } & \multicolumn{2}{c|}{$f$ type } & \multicolumn{2}{c}{$g$ type } \\
\hline$f$ type $(\mathrm{d})$ & $-0.533^{* *}$ & $-0.382^{*}$ & & & \\
& $(2.46)$ & $(1.77)$ & & & \\
Female $(\mathrm{d})$ & -0.389 & -0.400 & $-0.747^{*}$ & $-0.921^{* *}$ & -0.104 & 0.006 \\
& $(1.50)$ & $(1.57)$ & $(1.88)$ & $(2.41)$ & $(0.30)$ & $(0.02)$ \\
Age & $-0.135^{* * *}$ & $-0.088^{* * *}$ & $-0.153^{* * *}$ & $-0.096^{* * *}$ & $-0.118^{* * *}$ & $-0.081^{* * *}$ \\
& $(13.25)$ & $(7.64)$ & $(10.90)$ & $(5.39)$ & $(7.88)$ & $(5.22)$ \\
Father's ed. (years) & & $0.251^{* * *}$ & & $0.286^{* * *}$ & & $0.233^{* * *}$ \\
& & $(8.60)$ & & $(5.81)$ & & $(6.47)$ \\
No. siblings & & $-0.158^{* * *}$ & & $0.169^{* * *}$ & & $-0.123^{*}$ \\
& & $(2.94)$ & & $(2.09)$ & & $(1.68)$ \\
Prop. older siblings & & $-0.025^{* * *}$ & & $-0.022^{* * *}$ & & -0.312 \\
Constant & & $(5.12)$ & & $(3.89)$ & & $(0.89)$ \\
& $20.56^{* * *}$ & $16.28^{* * *}$ & $20.85^{* * *}$ & $15.99^{* * *}$ & $19.84^{* * *}$ & $16.18^{* * *}$ \\
$R^{2}$ & $(49.69)$ & $(25.88)$ & $(34.33)$ & $(15.57)$ & $(33.77)$ & $(20.47)$ \\
$F$ & 0.24 & 0.33 & 0.26 & 0.34 & 0.17 & 0.27 \\
$N$ & $66.21^{* * *}$ & $87.10^{* * *}$ & $61.13^{* * *}$ & $127.02^{* * *}$ & $31.08^{* * *}$ & $22.21^{* * *}$ \\
\hline
\end{tabular}

Notes

Absolute $t$ statistics in parentheses, based on the Huber-White sandwich variance estimator. $\mathrm{d}$ denotes a dummy variable. ${ }^{*}$ denotes a $10 \%$ significance level; ${ }^{* *}$ denotes a $5 \%$ significance level; and ${ }^{* * *}$ denotes a $1 \%$ significance level. 
The other columns of Table 2 reveal that the education choices of $f$ and $g$ type entrepreneurs are structured in somewhat different ways. In particular, female entrepreneurs and entrepreneurs with more older siblings obtain significantly and substantially less formal education on average if they come from business owning families compared with non-business owning families. This may suggest that later-born and female offspring are more likely than others to anticipate the prospect of family business succession, possibly in cases where their older siblings have revealed themselves to be unsuitable for succession. Alternatively, it is possible that these differences reflect some deeper unobserved heterogeneity between family types. One possible source of unobserved heterogeneity is intergenerational correlation in preferences and talents, as emphasized by Charles and Hurst (2003). Indeed, it might be thought that this source of unobserved heterogeneity could in fact explain why $f$ types have lower levels of education than $g$ types, since their parents also have low levels of education and tend to work in agriculture and retail with large family sizes (see Table 1). However, we do control for several of the factors associated with these types of family background, and even so the difference by entrepreneur type remains.

We followed up this investigation with a probit analysis, among $f$ type entrepreneurs only, asking whether these entrepreneurs took over a family firm (dependent variable $=1$ if so), or became an entrepreneur via a non-family takeover or a new start (dependent variable $=$ 0 for either). We conducted this analysis for entrepreneurs in all industry sectors, although the results were qualitatively unchanged when agriculture was excluded. According to the econometric estimates (available from the authors on request), the only significant explanatory variables were the number of siblings, with a negative effect which possibly reflects greater competition among offspring to be the successor; the year the entrepreneur entered (with a negative sign, indicating a decline in the phenomenon of offspring taking over family businesses); and whether the entrepreneur operates an agricultural business (with a positive sign). Perhaps surprisingly, later-born and female offspring were found to be slightly more likely to take over the family firm, but these effects were not significant (see the discussion in the preceding paragraph). So we can now turn our attention to what happens to $f$ and $g$ types who both have to choose between a non-family takeover or a new venture start.

\subsection{Determinants of the mode of entry: $N$ versus $T$}

The $f$ type entrepreneurs who have not matched with their family business as well as all $g$ type entrepreneurs choose between takeover $(\mathrm{T})$ and new start-up $(\mathrm{N})$. As noted in section 3, the advantage of taking over an existing firm rather than starting a new one is that it is less risky. We first verify this assertion. Defining payoffs as the income entrepreneurs earned from their businesses in 1994 (where income is measured comprehensively, including wages paid to entrepreneurs as well as returns to capital for unincorporated entrepreneurs), and measuring 
Table 3: Risk and mean returns by entry mode

\begin{tabular}{l|l|l|l}
\hline Income & All & New start-ups, N & Takeovers, T and F \\
\hline Mean & 70.97 & 67.68 & 87.25 \\
Median & 52.16 & 48.00 & 72.00 \\
St. Dev & 79.98 & 81.10 & 74.62 \\
C. V. & 1.14 & 1.20 & 0.86 \\
\hline$N$ & 541 & 450 & 91 \\
\hline
\end{tabular}

Notes

All values are in thousands of 1994 Dutch guilders. The first column provides values for the entire sample; the second and third columns distinguish start-ups from takeovers. The smaller sample size than in Table 1 reflects missing income data. St. Dev is standard deviation and C. V. is the coefficient of variation. The results are qualitatively unchanged if cases in the agricultural sector are excluded.

risk as the coefficient of variation of payoffs, ${ }^{13}$ Table 3 shows the mean and median incomes, as well as their standard deviations and coefficient of variation for the entire sample, and for start-ups and takeovers separately. The coefficient of variation of payoffs among $\mathrm{N}$ ventures clearly exceeds that among $\mathrm{T}$ ventures. Very similar results are observed if family takeovers are excluded.

To test the hypothesis that risk affects the entry mode, we estimated a simple probit model in which the dependent variable equals one if a start-up is chosen, and takes the value zero if a takeover is chosen. Note that a multinomial probit or logit model defined over the three entry modes $\mathrm{N}, \mathrm{T}$ and $\mathrm{F}$ is not appropriate here, as it cannot be used to investigate the effects of family background (Proposition 3) since $g$ types cannot by definition enter F.

Table 4 presents a sequence of results including progressively greater numbers of explanatory variables, in order to check the robustness of the results with respect to the inclusion of additional variables. Results are again reported for all industries; industry dummies are excluded from the final two columns for the reasons given earlier. Column I estimates a basic specification containing variables representing entrepreneur type and education achievement. There are two key findings. First, highly educated entrepreneurs are more likely to start up a new firm instead of entering entrepreneurship through takeover. These results support Proposition 2, the latter being consistent with the notion that education is especially productive in new venture starts by reducing search costs and enhancing success in managing high risk projects. $f$ type entrepreneurs turn out to be significantly more likely to choose $\mathrm{T}$ relative to N, compared with $g$ type entrepreneurs. This supports Proposition 3. The other columns

\footnotetext{
${ }^{13}$ As opposed to other measures of risk, such as the standard deviation, the coefficient of variation is independent of the mean value of the variable whose risk is measured. This is relevant because of the different mean net payoffs shown in Table 3 .
} 
Table 4: Determinants of new start-up versus takeover

\begin{tabular}{|c|c|c|c|c|}
\hline Variable & \multicolumn{4}{|c|}{ Marginal effects } \\
\hline & I & II & III & IV \\
\hline$f$ type $(\mathrm{d})$ & $\begin{array}{l}-0.040 \\
(1.83)\end{array}$ & $\begin{array}{l}-0.038^{*} \\
(1.82)\end{array}$ & $\begin{array}{l}-0.039^{*} \\
(1.87)\end{array}$ & $\begin{array}{l}-0.038^{*} \\
(1.85)\end{array}$ \\
\hline Education (years) & $\begin{array}{l}0.014^{* * *} \\
(4.29)\end{array}$ & $\begin{array}{l}0.011^{\text {*** }} \\
(2.92)^{2}\end{array}$ & $\begin{array}{l}0.011^{* * *} \\
(2.88)^{*}\end{array}$ & $\begin{array}{l}0.008^{* *} \\
(2.16)\end{array}$ \\
\hline Entry year (19..) & & $\begin{array}{l}0.001 \\
(0.94)\end{array}$ & $\begin{array}{l}0.001 \\
(1.02)\end{array}$ & $\begin{array}{l}0.001 \\
(0.42)\end{array}$ \\
\hline Female (d) & & $\begin{array}{l}0.040 \\
(1.57)\end{array}$ & $\begin{array}{l}0.034 \\
(1.26)\end{array}$ & $\begin{array}{l}0.028 \\
(1.05)\end{array}$ \\
\hline Age at entry & & $\begin{array}{l}-0.003^{* * *} \\
(2.68)\end{array}$ & $\begin{array}{l}-0.002 \\
(1.13)\end{array}$ & $\begin{array}{l}-0.002 \\
(1.21)\end{array}$ \\
\hline Gen labor exp (years) & & & $\begin{array}{l}-0.001 \\
(0.50)\end{array}$ & $\begin{array}{l}-0.001 \\
(0.42)\end{array}$ \\
\hline Industry exp (years) & & & $\begin{array}{l}0.001 \\
(0.86)\end{array}$ & $\begin{array}{l}0.001 \\
(0.91)\end{array}$ \\
\hline SE experience (years) & & & $\begin{array}{l}0.001 \\
(0.02)\end{array}$ & $\begin{array}{l}0.002 \\
(0.06)\end{array}$ \\
\hline Management exp (years) & & & $\begin{array}{l}-0.036^{*} \\
(1.67)\end{array}$ & $\begin{array}{l}-0.039^{*} \\
(1.82)\end{array}$ \\
\hline Entry cost in industry & & & & $\begin{array}{l}-0.0004^{* *} \\
(2.02)\end{array}$ \\
\hline Income risk in industry & & & & $\begin{array}{l}-0.0004 \\
(1.71)\end{array}$ \\
\hline Pseudo $R^{2}$ & 0.06 & 0.09 & 0.10 & 0.11 \\
\hline Wald $\chi^{2}$ & $23.91^{* * *}$ & $27.77^{* * *}$ & $29.72^{* * *}$ & $34.16^{* * *}$ \\
\hline$N$ & 636 & 616 & 605 & 605 \\
\hline
\end{tabular}

Notes

Dependent variable: binary, $=1$ if entry mode is a new start, and $=0$ if entry mode is a takeover of an existing firm. Absolute $t$ statistics in parentheses, based on the Huber-White sandwich variance estimator. d denotes a dummy variable: marginal effects are computed for discrete changes of the dummy variable from 0 to 1 . For continuous explanatory variables the effects are given in terms of quasi-elasticities. Asterisks as in Table 2. 
of Table 4 indicate that these results are broadly robust to the inclusion of other relevant covariates, although the size of the education effect is slightly attenuated as more explanatory variables are added and the sample size drops (owing to incomplete responses for some of the added variables).

To test the robustness of these results to the inclusion of control variables, column II adds the control variables 'entry year', 'female' and 'age at entry'. Family background and formal education remain statistically significant; the 'entry year' variable is insignificant and so is gender. Column II also shows that younger entrepreneurs are more inclined to start up a business than to take one over. The effect is quite small and turns out not to be robust to the inclusion of additional covariates (see the other columns of the table). We therefore conclude that there is no robust effect of gender or age on entrepreneurial entry mode.

Column III adds to the specification other dimensions of formal human capital, in the form of various kinds of experience. This enables Propositions 4 and 5 to be tested. The only variable in this category that is marginally significant in all equations is years of previous experience of managing people, which is associated with a higher probability of becoming an entrepreneur through takeover instead of start-up. This is consistent with Proposition 4, although the size and significance of this effect are modest. In contrast, there is no significant effect of other types of experience on the mode of entry. Hence Proposition 5 is not supported.

Column IV includes controls for (industry-specific) entry capital requirements and risk, as defined in the previous section. These are added in order to test Proposition 6, which stated that greater risk and start-up capital requirements decrease the probability entrepreneurs will start a new firm rather than take over an existing one. The results show that takeover becomes relatively more attractive when industry entry is more risky and/or more expensive. These findings are consistent with Proposition 6, though the entry risk variable is only marginally significant.

\subsection{Robustness checks}

One robustness check dropped all observations relating to agriculture from the specification estimated in Table 4. The results are qualitatively unchanged, with two exceptions. One is that the effect of $f$ type on entry mode choice becomes more significant in the first two columns when agricultural entrepreneurs are dropped; the other is that the effects from years of education become marginally less significant.

We also checked whether there is a potential problem of survivorship bias. Our crosssection of data includes only entrepreneurs who are still in business. The danger is that $\mathrm{N}$ entrepreneurs are more prone to failure than $\mathrm{T}$ and $\mathrm{F}$ entrepreneurs: hence we might oversample abler (better educated) entrepreneurs who are disproportionately found in the $\mathrm{N}$ mode. This could impart an upward bias to the estimates on the role of education in Table 4. Put another way, interacting education with the duration of time spent in the current business 
should enter with a positive coefficient if survival bias is a salient issue. Consequently we re-ran each probit in Table 4, including this interaction term together with years of education and duration entered separately. In all cases the interaction term was insignificant.

Another consideration is that some self-employed parents run businesses which cannot be passed on or sold - for example, window cleaners, lawyers and doctors. Despite their children being unable to inherit a business in the conventional sense, they are nevertheless classified as $f$ types. We could not control for parental occupation in sufficient detail to test the robustness of our results to the omission of these cases; but we doubt this consideration affects the results in a material way. If anything, it is likely to increase the degree of imprecision of our results, making the significant relationships which are uncovered more noticeable.

Finally, we tested whether the mode of entry might be affected by the existence of capital constraints. For example, if entrepreneurs are obliged to select an inexpensive mode of entry because capital required in their preferred entry mode is not forthcoming, biased results might ensue. To test this possibility, we constructed two measures of initial constraints. First, following Parker and van Praag (2006), the extent of borrowing constraints is measured directly as $B C:=100 \times(1-r) \geq 0$, where $r$ is the ratio of initial capital invested and initial capital required (see Table 1 for descriptive statistics). Also, a dummy variable for having experienced capital constraints is defined as equal to one if $B C>0$ and equal to zero if $B C=0$. This second constraint measure reflects whether entrepreneurs face any constraint or not. It turns out that less than $33 \%$ of the entrepreneurs experienced any capital constraint at the time of entry, while only $12 \%$ claimed to be constrained by $60 \%$ or more of their required capital. Across the sample, the average extent of capital constraints $B C$ is only $17.8 \%$. This suggests that capital constraints are not an issue for the majority of respondents. Furthermore, Table 1 reveals no significant difference in $B C$ by family background. Nevertheless, to err on the side of caution, we re-ran all of the specifications reported above for all respondents apart from those claiming to be constrained by $60 \%$ or more of their required capital. The results, which are available from the authors on request, remained qualitatively unchanged.

\section{Discussion and conclusion}

Overall, our empirical tests support most of the propositions advanced in this article. Entrepreneurs who come from business-owning families, and entrepreneurs with high levels of managerial experience, are both more inclined to take over an existing firm than to start-up a new one, whereas formal education increases the probability of brand new venture starts. Furthermore, required start-up capital and risk diminish the probability of new venture starts as well.

What are the implications of our results for policy makers, practitioners and entrepreneurship researchers? To the extent that one can generalize from one set of results, we would 
argue that practitioners and policy-makers should start to recognize that entrepreneurs can and do choose between multiple modes of entry, and incorporate this insight in the design of public policy programs. For example, entrepreneurship education programs often focus on new start-ups, neglecting the important entry route of takeovers. As we have seen, takeovers seem to attract individuals with different skill sets to new starts, combining less formal education with greater levels of managerial experience. In view of the current scarcity of takeover candidates in Europe and parts of North America it may be advisable to extend these programs to educate aspiring entrepreneurs about takeovers as well.

More generally, this information could help policy-makers target participants in business support programs. For example, if takeover candidates really are more readily found among the offspring of entrepreneurs, practitioners might be able to use this information to foster closer networks of family firms which can organize markets to match supply and demand of firm takeovers across families to make the succession process smoother. Since the process of firm takeover no longer takes place automatically within the family, various families could be brought together in such markets where people coming from business owning firms from different generations meet as potential buyers and sellers.

We believe that future research can usefully build on our initial work. At present, the literature contains many studies which conflate the different modes of entry. This can introduce an aggregation problem, leading for example to lower estimated effects of education on new venture creation if takeovers are mistakenly included in the sample of venture starts. Arguably, greater consistency about the treatment of different entry modes might clarify research findings across studies and reduce the incidence of inconsistent or contradictory results. There can be policy benefits from this as well. For instance, our results suggest that higher costs of starting a new firm will lead to fewer new starts but more takeovers. This opportunity to substitute entry into a different mode can be overlooked by traditional research methods which focus purely on new venture creation. The danger is that the importance of borrowing constraints on entrepreneurship as a whole will be overstated (Hurst and Lusardi, 2004) with the consequence that policy recommendations will be distorted.

Clearly, more research is needed to broaden the findings and extend the analysis in several novel and important directions. The most obvious empirical question is whether our results also hold in countries other than the Netherlands, and whether there are important differences between and within EU states vis-à-vis the US. Also, on a conceptual level, the analysis could be usefully extended to study the family firm succession issue in more detail. That might recognize the potential for conflicts within families at the same time as taking account of entrepreneur-financier frictions. More generally, we believe that there are substantial potential gains to be made by building on the approach of this paper, and analyzing succession from the viewpoint of successors, rather than just that of existing founders - which is where most research has focused to date. 


\section{References}

Acs, Z. and C. Armington (2006) Entrepreneurship, Geography, and American Economic Growth, Cambridge: Cambridge University Press.

Astebro, T. and I. Bernhardt (2003) Start-up financing, owner characteristics, and survival, Journal of Economics and Business, 55, pp. 303-19.

Astebro, T. and P. Thompson (2007) Entrepreneurs: Jacks of All Trades or hobos? Working paper

Becker, G. S. (1964) Human Capital, NBER, New York

Bennedsen, M., Nielsen, K. M., Perez-Gonzalez, F., and D. Wolfenzon (2006) Inside the family firm: The role of families in succession decisions and performance, NBER Working Paper No. 12356, Cambridge, MA.

Black, S., Devereux, P., and K. Salvanes (2005) The more the merrier? The effect of family composition on children's outcomes, Quarterly Journal of Economics, 120, pp. 669-700.

Boheim, R. and M. P. Taylor (2001) Job search methods, intensity and success in Britain in the 1990s, Mimeo, Institute for Social $\&$ Economic Research, University of Essex.

Brouwer, E., Edelmann, E., van Praag, C. M., and B. M. S. van Praag (1996) Determinants of success or failure of Dutch entrepreneurs, Unpublished report, Wetenschappelijke Raad voor het Regeringsbeleid, Voorstudie, The Netherlands.

Bruce, D. and H. J. Schuetze (2004) The labour market consequences of experience in selfemployment, Labour Economics, 11, pp. 575-98

Burkart, M., Panunzi, F., and A. Shleifer (2003) Family firms, Journal of Finance, 58, pp. 2167-2201.

Card, D. (2001) Estimating the returns to schooling: progress on some persistent econometric problems, Econometrica, 69, pp. 1127-60.

Caselli, F. and N. Gennaioli (2005) Credit constraints, competition, and meritocracy, Journal of the European Economic Association, 3(2-3), pp. 679-89.

Casson, M. (1995) Entrepreneurship and Business Culture, Edward Elgar, Aldershot UK

Chaganti, R. and J. A. Schneer (1994) A study of the impact of owner's mode of entry on venture performance and management patterns, Journal of Business Venturing, 9, pp. 24360

Charles, K. K. and E. Hurst (2003) The correlation of wealth across generations, Journal of Political Economy, 111, pp. 1155-82.

Cocco, J. F, Gomes, F. J., and P. J. Maenhout (2005) Consumption and portfolio choice over the life-cycle, Review of Financial Studies, 18, pp. 491-533.

Colombier, N. and D. Masclet (2008) Intergenerational correlation in self-employment: some further evidence from French ECHP data, Small Business Economics, 30, pp. 423-37

Commission of the European Communities (2006) Transfer of Businesses: Continuity through a new beginning, EC, Brussels. 
Cooper, A. and W. Dunkelberg (1986) Entrepreneurship and paths to business ownership, Strategic Management Journal, 7, pp. 53-68.

Douhan, R.D. (2009) Compulsory education and jack-of-all-trades entrepreneurs, IFN Working Paper.

European Commission (2003) Green Paper - Entrepreneurship in Europe, EC, Brussels.

Eurostat (2000) Enterprises in Europe, Luxembourg: Eurostat.

Fairlie, R. W. (2004) Does business ownership provide a source of upward mobility for blacks and Hispanics?, in Holtz-Eakin, D. and H. S. Rosen (eds.) Public Policy and the Economics of Entrepreneurship, MIT Press, Cambridge, MA., pp. 153-79.

Fairlie, R. W. and A. Robb (2007) Families, human capital, and small business: Evidence from the Characteristics of Business Owners Survey, Industrial and Labor Relations Review, $60(2)$, pp. 225-45.

Gomes, F. and A. Michaelides (2005) Optimal life cycle asset allocation: understanding the empirical evidence, Journal of Finance, 60, pp. 869-904.

Hayward, M. L. A., D. A. Shepherd and D. Griffin (2006) A hubris theory of entrepreneurship, Management Science, 52, pp. 160-72.

Holmes, T. J. and J. A. Schmitz (1990) A theory of entrepreneurship and its application to the study of business transfers, Journal of Political Economy, 98, pp. 265-94.

Hurst, E. and A. Lusardi (2004) Liquidity constraints, household wealth, and entrepreneurship, Journal of Political Economy, 112, pp. 319-47.

Hyytinen, A. and P. Rouvinen (2008) The labour market consequences of self-employment spells: European evidence, Labour Economics, 15, pp. 246-71

Jovanovic, B. (1982) Selection and the evolution of industry, Econometrica, 50, pp. 649-70

Landier, A. (2004) Entrepreneurship and the stigma of failure, Mimeo, Stern School of Business, New York University.

Lazear, E. P. (2005) Entrepreneurship, Journal of Labor Economics, 23, pp. 649-80.

Lentz, B. F. and D. N. Laband (1990) Entrepreneurial success and occupational inheritance among proprietors, Canadian Journal of Economics, 23, pp. 563-79.

Lowe, A. L. and A. A. Ziedonis (2006) Overoptimism and the performance of entrepreneurial firms, Management Science, 52, pp. 173-Ů86.

Nicolaou, N., S. Shane, L. Cherkas, J. Hunkin and T. D. Spector (2008) Is the tendency to engage in entrepreneurship genetic?, Management Science, 54, pp. 167-179.

Oreopoulos, P. (2006) Estimating average and local average treatment effects of education when compulsory schooling laws really matterm American Economic Review, 96(1), pp. 15275

Parker, S. C. (2007) Entrepreneurial learning and the existence of credit markets, Journal of Economic Behavior \& Organization, 62(1), pp. 37-46.

Parker, S. C. (2009) The Economics of Entrepreneurship. Cambridge: Cambridge University 
Press.

Parker, S. C. and C. M. van Praag (2006) Schooling, capital constraints and entrepreneurial performance: The endogenous triangle, Journal of Business $\&$ Economic Statistics, 24, pp. 416-31.

Polkovnichenko, V. (2003) Human capital and the private equity premium, Review of Economic Dynamics, 6, pp. 831-45.

Puri, M. and D. T. Robinson (2007) Optimism and economic choice, Journal of Financial Economics, 86(1), pp. 71-99.

Riley, J. (2002) Weak and strong signals, Scandinavian Journal of Economics, 104, pp. 213236.

Robinson, D.T. (2009) Getting an early start in self-employment, Working Paper, Duke University.

Silva, O. (2007) The jack-of-all-trades entrepreneur: innate talent or acquired skill? Economics Letters, 97, pp. 118-123.

Spence, A. 1973. Market Signalling: Information Transfer in Hiring and Related Processes, Harvard University Press, Cambridge, MA.

Ucbasaran, D., P. Westhead and M. Wright (2009) The extent and nature of opportunity identification by repeat entrepreneurs, Journal of Business Venturing, 24, pp. 99-115.

Van Der Sluis, J., M. Van Praag and W. Vijverberg (2008) Education and entrepreneurship selection and performance: a review of the empirical literature, Journal of Economic Surveys, $22(5)$, pp. $795-841$.

Van Praag, C. M. (2003) Business survival and success of young small business owners, Small Business Economics, 21(1), pp. 1-17.

Van Praag, C. M. (2005) Successful Entrepreneurship: Confronting Economic Theory with Empirical Practice, Cheltenham: Edward Elgar.

Wagner, J. (2003) Testing Lazear's jack-of-all-trades view of entrepreneurship with German micro data Applied Economics Letters 10(11): 687-689. 